\title{
Article \\ Advanced Air Mobility: Opportunities and Challenges Deploying eVTOLs for Air Ambulance Service
}

\author{
Rohit Goyal ${ }^{1, *}$ and Adam Cohen ${ }^{2}$ (D) \\ 1 Independent Researcher, Boston, MA 02128, USA \\ 2 Transportation Sustainability Research Center, University of California, Berkeley, CA 94720, USA; \\ apcohen@berkeley.edu \\ * Correspondence: rohitgoyal1690@gmail.com
}

check for updates

Citation: Goyal, R.; Cohen, A. Advanced Air Mobility:

Opportunities and Challenges

Deploying eVTOLs for Air

Ambulance Service. Appl. Sci. 2022,

12, 1183. https://doi.org/

10.3390/app12031183

Academic Editor: Ho Yon Hwang

Received: 20 October 2021

Accepted: 4 January 2022

Published: 24 January 2022

Publisher's Note: MDPI stays neutral with regard to jurisdictional claims in published maps and institutional affiliations.

Copyright: (c) 2022 by the authors. Licensee MDPI, Basel, Switzerland. This article is an open access article distributed under the terms and conditions of the Creative Commons Attribution (CC BY) license (https:// creativecommons.org/licenses/by/ $4.0 /)$.

\begin{abstract}
Advanced air mobility (AAM) is a broad concept enabling consumers access to on-demand air mobility, cargo and package delivery, healthcare applications, and emergency services through an integrated and connected multimodal transportation network. While a number of technical and social concerns have been raised about AAM, early use cases for emergency response and aeromedical transport may be key to demonstrating the concept and building public acceptance. Using a fivestep multi-method approach consisting of preliminary scoping, modeling performance metrics, developing baseline assumptions, analyzing scenarios, and applying a Monte Carlo sensitivity analysis, this study examines the potential operational and market viability of the air ambulance market using a variety of aircraft and propulsion types. The analysis concludes that electric vertical take-off and land (eVTOL) aircraft could confront a number of operational and economic challenges for aeromedical applications compared to hybrid vertical take-off and land (VTOL) aircraft and rotorcraft. The study finds that technological improvements such as reduced charge times, increased operational range, and battery swapping could make the eVTOL aircraft more reliable and costeffective for aeromedical transport.
\end{abstract}

Keywords: advanced air mobility; urban air mobility; emergency response; air ambulance; electric vertical take-off and land; VTOL; eVTOL

\section{Introduction}

Advanced air mobility (AAM) is a broad concept enabling consumers access to ondemand air mobility, cargo and package delivery, healthcare applications, and emergency services through an integrated and connected multimodal transportation network [1,2]. While AAM may be enabled by the convergence of several factors, a number of challenges such as community acceptance, safety, social equity, planning, airspace management, and others could create barriers to mainstreaming [2,3]. While a number of technical and social concerns have been raised about AAM, early use cases for emergency response and aeromedical transport may be key to demonstrating the concept and building public acceptance [4]. Examples of emergency response use cases include air ambulance, emergency supply delivery, organ transport, search and rescue operations, firefighting, and other disaster response and humanitarian applications.

Broadly, the medical transport sector provides a combination of patient ground and air transportation. The aircraft and vehicles that can be used in a medical emergency mission and provide medical transport include: (1) ground vehicles, (2) rotorcraft (also known as rotary-wing and helicopters), and fixed-wing aircraft. As of 2016, there were an estimated 50,000 ground vehicles for short-distance patient transport to medical facilities across the United States [5]. In comparison, there were 1411 aircraft and rotorcraft providing aeromedical transport in the U.S as of 2017 [5]. This paper focuses on the air ambulance use case which includes medical transport to and from a hospital (or other medical facility) for emergency and non-emergency care. 


\section{Literature Review}

Around the world, communities are experimenting with the use of advanced air mobility to serve a variety of medical response and pandemic use cases such as social distancing reminders, essential equipment and medical supply delivery, and virus detection [6-9]. Airspace Systems, a California AAM startup, has developed software that can help public agencies use drones to monitor social distancing and face mask compliance [10]. Similarly, in Elizabeth, New Jersey, the police department has used drones equipped with an automated message to remind the public to social distance during the pandemic [11]. In the U.S., the United Parcel Service (UPS) and CVS Pharmacy began using Matternet M2 drones to deliver prescription medications to a retirement community in Florida during a COVID-19 stay-at-home order in May 2020 [12].

In remote areas, advanced air mobility has the potential to reduce the time to access medical supplies and testing from hours using surface transportation to $15 \mathrm{~min}$ by drone in some cases [13]. In parts of Africa, the use of drones is becoming a growing part of rural healthcare delivery. In Rwanda, Zipline has used fixed-wing drones to airdrop medical supplies and ferry tests from numerous hospitals across the region [14]. In response to the global pandemic, the company began transporting COVID-19 test samples from remote parts of Ghana that do not have testing facilities to laboratories in more populated regions of the country [15]. The service has also expanded access to medical care for patients who are unable to travel due to COVID-19 restrictions. For example, drones are being used to deliver cancer drugs to patients in remote villages who are unable to travel to oncology centers during the pandemic [16].

These case studies represent a handful of emerging examples of how advanced air mobility has the potential to expand access to healthcare $[17,18]$. In spite of the large number of potential aeromedical use cases, air ambulances only serve a small percentage of critical medical transports [5]. Historically, the high cost of air ambulance service limits the use of air transportation to patients in remote areas or the most critical medical situations where minimizing transport time to a hospital is critical to saving a patient's life [19].

Although existing studies on the use of electric aircraft and other emerging aviation technologies for aeromedical use are limited, an emerging body of research suggests that emergency medical AAM services may confront a number of technical and business model challenges. Yet, these same aeromedical use cases may be important to building public acceptance of novel aircraft designs and technologies [20]. A study by Chappelle et al. [21] found that near-term electric aircraft are not expected to meet the technical requirements of air ambulance service, nor will they likely provide cost savings over existing services using helicopters. Internationally, Mihara et al. [22] conducted a cost analysis of electric vertical take-off and land (eVTOL) aircraft for an air ambulance system in Japan. The study's scenario analysis concludes that differences in battery capacity can have notable differences in future cost models due to the relatively high cost of battery replacements. Mihara et al. [22] also compare the potential viability of eVTOLs to existing helicopters using a standardized operational concept for air ambulance service. This study builds upon prior literature by studying the feasibility of eVTOLs for aeromedical use in the United States.

According to the National Emergency Medical Services Information System (NEMSIS) and the National Association of State Emergency Medical Service Officials (NASEMSO), there are an estimated 36 million medical transport trips served by ambulances annually. However, only approximately $1.5 \%$ of these trips (roughly 550,000 ) are served by air ambulances every year [23,24]. As of 2017, there are 1049 rotary-wing air ambulances operating from 908 bases across the U.S. serving $84.3 \%$ of Americans within a 20 min response time [5]. While historical data indicates that the number of aircraft and bases increased between 2005 and 2015, a number of business and legislative factors have contributed to the consolidation of service providers. These developments have caused a stabilization in the number of aircraft while the number of bases continue to increase. 
Both ground and air ambulances have nine service levels, as defined by the U.S. Centers for Medicare and Medicaid Services (CMS) $[25,26]$. Each service level has different medical equipment, crew, and vehicle requirements and can be served either by a ground ambulance or an air ambulance (either helicopter or fixed-wing aircraft) depending on local emergency service dispatch protocol. A description of these nine service levels and crew requirements are summarized in Tables 1 and 2, respectively. A single emergency eVTOL will require four full time pilots, four full time flight nurses, and four full time paramedics with Commission on Accreditation of Medical Transport Systems (CAMTS) accreditation and annual training according to Federal Aviation Administration (FAA) duty hour requirements.

Table 1. Nine ambulance service levels.

\begin{tabular}{|c|c|c|}
\hline & CMS Service Level & Description \\
\hline \multirow{7}{*}{$\begin{array}{l}\text { Ground } \\
\text { Ambulance }\end{array}$} & $\begin{array}{l}\text { Basic Life Support (BLS) Non- } \\
\text { Emergent }\end{array}$ & Provision of medical supplies and services \\
\hline & BLS Emergency & $\begin{array}{c}\text { Provision of BLS services, as specified above, in the context of an } \\
\text { emergency response }\end{array}$ \\
\hline & Advanced Life Support (ALS) Non-Emergent & $\begin{array}{l}\text { Provision of medically necessary supplies and services including the } \\
\text { provision of an ALS assessment or at least one ALS intervention }\end{array}$ \\
\hline & ALS1 Emergent & Provision of ALS services in the context of an emergency response \\
\hline & $\begin{array}{l}\text { ALS2 (3 Separate } \\
\text { Medications by IV) }\end{array}$ & $\begin{array}{c}\text { Provision of ALS services in the context of an emergency response plus } 3 \\
\text { separate medications by IV }\end{array}$ \\
\hline & Specialty Care Transport (SCT) & $\begin{array}{l}\text { Interfacility transportation of a critically injured or ill beneficiary } \\
\text { including the provision of medically necessary supplies and services }\end{array}$ \\
\hline & Specialty Care Transport (SCT) & $\begin{array}{l}\text { ALS services provided by an entity that does not provide the } \\
\text { ambulance transport }\end{array}$ \\
\hline \multirow{2}{*}{$\begin{array}{c}\text { Air } \\
\text { Ambulance }\end{array}$} & Rotorcraft (Helicopters) & BLS or ALS type service for short distances that require rapid air transport \\
\hline & Fixed Wing Aircraft & $\begin{array}{c}\text { BLS or ALS type service for long distances that require rapid inter-city air } \\
\text { transport }\end{array}$ \\
\hline
\end{tabular}

Summarized from [23].

Table 2. Crew service requirements.

\begin{tabular}{|c|c|c|c|c|c|}
\hline CMS Service Level & Driver $^{1} /$ Pilot $^{2}$ & $\begin{array}{l}\text { Emergency Medical } \\
\text { Technician (EMT) }^{3}\end{array}$ & Paramedic $^{4}$ & $\begin{array}{c}\text { Health } \\
\text { Professional }\end{array}$ & Total \\
\hline BLS Non-Emergent & 1 & 2 & - & - & 3 \\
\hline BLS Emergency & 1 & 2 & - & - & 3 \\
\hline ALS Non-Emergent & 1 & 1 & 1 & - & 3 \\
\hline ALS1 Emergent & 1 & 1 & 1 & - & 3 \\
\hline $\begin{array}{l}\text { ALS2 ( } 3 \text { Separate } \\
\text { Medications by IV) }\end{array}$ & 1 & 1 & 1 & - & 3 \\
\hline SCT & 1 & 1 & - & $1+$ & $3+$ \\
\hline PI & 1 & 1 & - & $1+$ & $3+$ \\
\hline Rotorcraft (Helicopters) & 1 & 1 & 1 & - & 3 \\
\hline Fixed Wing Aircraft & $1+$ & $1+$ & - & $1+$ & $3+$ \\
\hline & \multicolumn{5}{|c|}{$\begin{array}{l}{ }^{1} \text { Driver: Drives the patients from place to place. }{ }^{2} \text { Pilot: Required to conduct flight planning, preflight risk } \\
\text { analyses, safety briefings for medical personnel, and the establishment of operations control centers (OCC) for } \\
\text { certain operators to help with risk management and flight monitoring. }{ }^{3} \text { EMT: Entry-level EMS healthcare } \\
\text { professional trained in BLS, anatomy/physiology, pathophysiology, pharmacology, ECG monitoring, advanced } \\
\text { airway management (supraglottic airways) and spinal immobilization. }{ }^{4} \text { Paramedic: emergency ambulance } \\
\text { practitioner. Trained in advanced pharmacology, advanced airway management, advanced life support, etc. } \\
\text { Health Professional: trained to paramedic level plus IV and IO access, a wide range of medications, tracheal } \\
\text { intubation, manual defibrillator, etc. }\end{array}$} \\
\hline
\end{tabular}




\section{Methodological Overview}

The authors conducted a literature review of air ambulance service characteristics, operational assumptions, and potential applications of novel aircraft. Between Summer 2017 and Winter 2019, as part of a National Aeronautics and Space Administration (NASA) market study, the authors established a study advisory group (SAG) to solicit feedback on key assumptions from more than 50 public and private sector thought leaders to inform this research. SAG members included senior professionals and subject matter experts from NASA, the FAA, the National Transportation Safety Board (NTSB), the North Carolina Department of Transportation, New York City, the city of Los Angeles, Los Angeles World Airports, the International Civil Aviation Organization (ICAO), and numerous manufacturers, startups, and academic institutions. Public sector participants included directors of the FAA's Aviation Plans and Policy Office, the Office of International Affairs, the Unmanned Aircraft Systems (UAS) Integration Office, and a former NTSB chairman. Manufacturers and startups representing a diverse set of planned airframes were also included as part of the SAG.

Using input from the SAG, the authors developed a five-step process to analyze the air ambulance market. Collectively, these five steps (described below) included calculating key business and operational metrics, such as number of flights, potential revenue, operating costs, transport volumes and distribution, and infrastructure availability (e.g., number, location, and capacity of hospitals and other medical facilities with helipads/vertipads).

\section{Step 1. Preliminary Scoping}

The first step included defining operational concepts for the air ambulance use case. CMS service level, regardless of ground or air ambulance, consists of six key temporal phases: (1) dispatch time; (2) chute time; (3) response time; (4) time on scene; (5) transport time; and (6) return time.

1. Dispatch time is measured from the time a telephone dispatcher receives a call until they dispatch an ambulance.

2. Chute is the time from when a call is dispatched to the time an ambulance begins to travel to the location.

3. Response time is measured from the time an ambulance is en route until the ambulance reaches the scene.

4. The time on scene is measured by the time a unit arrives on scene to the time a unit departs the scene.

5. Transport time is measured from the moment an ambulance leaves the scene until a patient arrives at their destination.

6. Return time is the time it takes for an ambulance to leave their destination and return to service.

Collectively, the entire time period from dispatch to placing an ambulance back in service is referred to as total call time. The authors assumed that dispatch, chute, and time on scene are fixed time intervals not affected by the aircraft type. Therefore, only response time, transport time, and return time can be improved through aircraft enhancements. Each of these temporal phases and times measured in minutes are shown in Figure 1. 


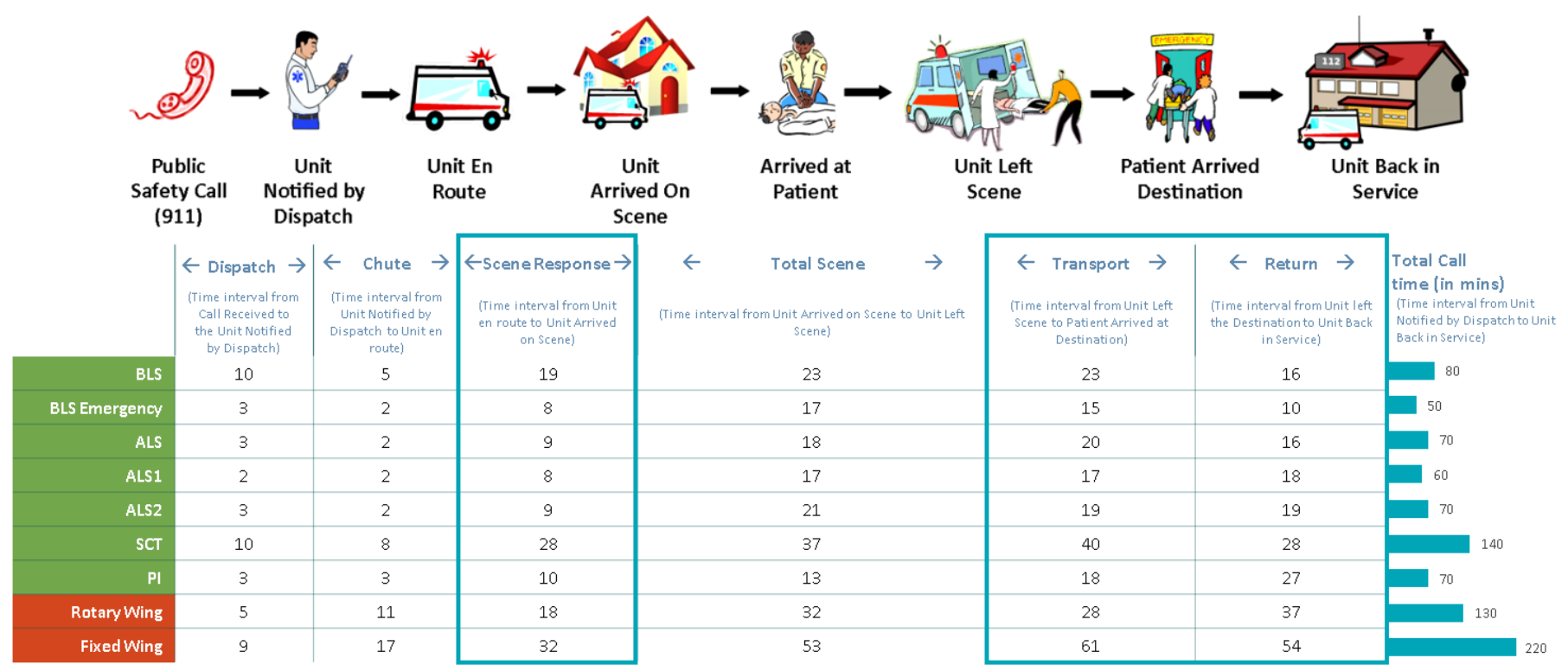

Figure 1. Air ambulance concept of operations and temporal phases (times shown in minutes). Source: Data from [27].

Step 2. Inventorying Operational Assumptions

The second step involved developing operational assumptions and modeling key performance metrics such as crew size and flight profiles. To do this, Section 3.1 outlines more specific operating assumptions that were used as part of Step 2.

\section{Step 3. Baseline Calculations}

Next, the authors calculated the cost of emergency medical service for different aircraft types proposed to serve the air ambulance market. Each cost, such as capital, maintenance, batteries, electric charging, vertiports, and personnel were individually modeled. Section 3.1 outlines the specific process used to formulate the baseline calculations for each aircraft type.

\section{Step 4. Monte Carlo Sensitivity Analysis}

Fourth, the authors performed a Monte Carlo sensitivity analysis simulating 10,000 randomly generated air ambulance missions. Section 4 summarizes the methodology used to conduct the Monte Carlo simulation.

\section{Step 5. Scenario Analysis}

In the final step, the authors developed scenarios using different operating models, such as battery recharging during patient disembarkation and battery swapping. Section 4.1 explains the specific methodology used to model each scenario.

The methodological assumptions and findings from each of these steps in the analytical process are described in greater detail in Sections 3.1 and 4, respectively. All data used in the analysis were from 2018 unless otherwise noted.

\subsection{Methodological Assumptions}

For this analysis, the authors introduced gasoline hybrid electric (referred to as 'hybrid') and eVTOL aircraft into the air ambulance marketplace. Based on a literature review and information obtained from the study advisory group, the authors assumed an average cruise speed of $402 \mathrm{~km}$ per hour $(\mathrm{kph}) / 250$ miles per hour (mph) for hybrid aircraft, 241 $\mathrm{kph} / 150 \mathrm{mph}$ for eVTOLs, and $160 \mathrm{kph} / 100 \mathrm{mph}$ for conventional helicopters.

The air ambulance flight profile consists of three primary mission phases (shown in Figure 2). This includes: Response (A-F), Transport (H-M), and Return to Service (N-R). The authors assumed that each of these sub-missions are flown with similar profiles (i.e., 
Taxi, Hover Climb, Climb, Cruise, Descend, Hover Descend, and Taxi). While on-scene, it was assumed that the air ambulance is operating in a taxi configuration (e.g., idle on the ground). However, it is important to note that this methodology does not account for minor operational variations such as an eVTOL landing while on scene versus hovering in place to load a patient using a litter (rescue basket). These types of operational decisions are influenced by a number of unique circumstances such as weather, clearance to land, patient condition, risk to aircrew, and other factors. Total flight time represents the sum of response, transport, and return time. After completing the patient transport to the hospital, the air ambulance returns to its base (N-R) and is prepared to return to service (R-Q). For helicopters, return to service preparation time includes the time to refuel, whereas for eVTOLs, this period refers to the time required to recharge batteries for the next mission. The authors assumed that for hybrid aircraft, take-off landing is flown on electric (battery) power while remaining phases of flight are flown using a gas turbine engine.

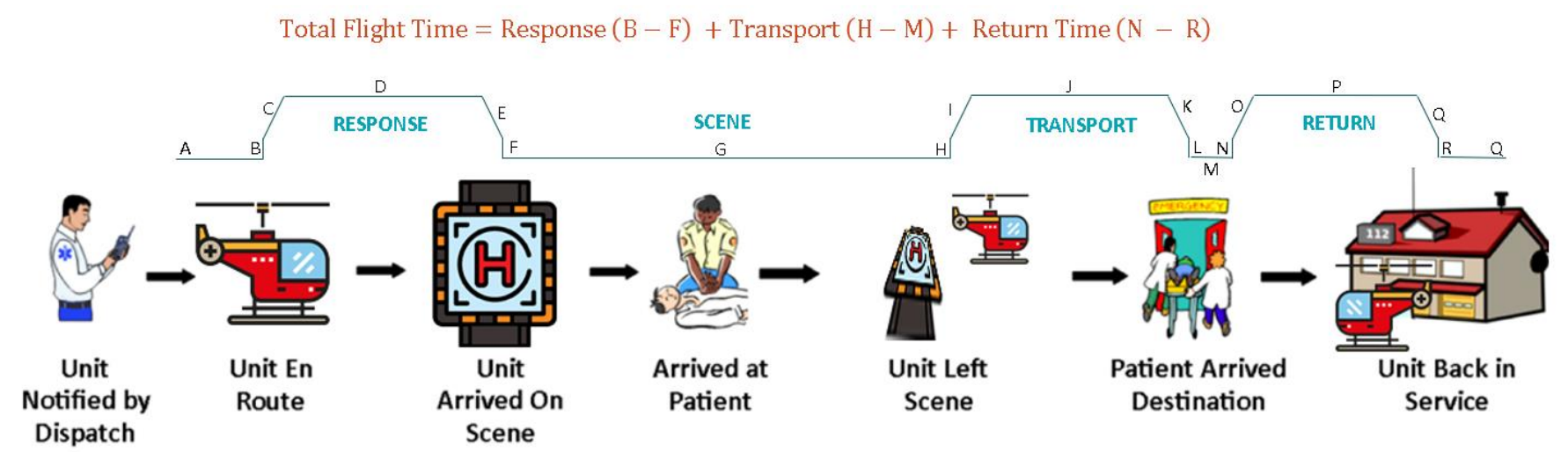

Figure 2. Flight profile for the air ambulance use case.

For this analysis it was assumed that eVTOL and hybrid aircraft transport one patient between an incident scene and the hospital. It was assumed that each aircraft would fly an average cruise altitude between 500 to 5000 feet above ground level. Per FAA duty hour requirements, a single emergency eVTOL and hybrid was required to have four full time pilots, four full time flight nurses, and four full time paramedics with CAMTS accreditation. Key operational assumptions used in this analysis are shown in Table 3.

Table 3. Key operational assumptions.

\begin{tabular}{|c|c|c|c|c|}
\hline Parameter & Sub Parameter & Minimum & Maximum & Data Source \\
\hline \multirow{7}{*}{$\begin{array}{c}\text { Aircraft } \\
\text { Assumptions }\end{array}$} & Cruise Speed (for eVTOL) ${ }^{1}$ & $125 \mathrm{mph}$ & $175 \mathrm{mph}$ & [21] \\
\hline & Cruise Speed (for Hybrid) ${ }^{2}$ & $200 \mathrm{mph}$ & $300 \mathrm{mph}$ & [28] \\
\hline & Equivalent Number of Seats ${ }^{2}$ & 5 & 8 & [29] \\
\hline & Reserve (mins) & 20 & 30 & [30] \\
\hline & Range (miles) & $50+$ Reserve & $200+$ Reserve & [28] \\
\hline & Battery Capacity (kWh) & $100 \mathrm{kWh}$ & $150 \mathrm{kWh}$ & [31] \\
\hline & Annual number of Transports ${ }^{3}$ & 300 & 400 & [5] \\
\hline \multirow{4}{*}{$\begin{array}{l}\text { Crew/Payroll } \\
\text { Assumptions }\end{array}$} & Pilot Salary (USD per year) & 60,000 & 100,000 & \multirow{4}{*}{ [32] } \\
\hline & Paramedic (USD per year) & 50,000 & 75,000 & \\
\hline & EMT (USD per year) & 60,000 & 90,000 & \\
\hline & Mechanic Salary (USD per year) ${ }^{4}$ & 50,000 & 90,000 & \\
\hline
\end{tabular}


The authors analyzed the technical feasibility of the air ambulance use case using nine types of VTOL aircraft shown in Table 4. Each cost such as capital, maintenance, batteries, electric charging, vertiports, and personnel were individually modeled. The cost per transport for each aircraft type is calculated as a sum of direct operating cost (DOC) and indirect operating cost (IOC). DOC includes capital, energy, battery, crew, maintenance, and insurance costs, while IOC is estimated as a percentage range (10 to 30\%) of DOC. Each cost component of the DOC is individually modeled according to Figure 3 . The number of aeromedical transports required and performed were modeled using hourly demand distributions for each of the different scenarios. Due to range requirements, only electric and hybrid versions of tilt rotor and tilt wing were found to be suitable.

Table 4. Aircraft/Rotorcraft performance assumptions.

\begin{tabular}{|c|c|c|c|c|c|}
\hline $\begin{array}{c}\text { Propulsion } \\
\text { Type }\end{array}$ & Classification & $\begin{array}{l}\text { Min Cruise } \\
\text { Speed (mph) }\end{array}$ & $\begin{array}{l}\text { Max Cruise } \\
\text { Speed (mph) }\end{array}$ & $\begin{array}{l}\text { Min Range } \\
\text { (miles) }\end{array}$ & $\begin{array}{c}\text { Max Range } \\
\text { (miles) }\end{array}$ \\
\hline \multirow{6}{*}{ Electric } & Multi Rotor & 40 & 60 & 30 & 50 \\
\hline & Tilt Rotor & 110 & 190 & 90 & 150 \\
\hline & Lift and Cruise & 110 & 190 & 50 & 80 \\
\hline & Tilt Wing & 110 & 190 & 170 & 290 \\
\hline & Tilt Duct & 110 & 190 & 110 & 180 \\
\hline & $\begin{array}{l}\text { Compound } \\
\text { Helicopter }\end{array}$ & 110 & 190 & 90 & 150 \\
\hline \multirow{2}{*}{ Hybrid } & Multi Rotor & 40 & 60 & 50 & 80 \\
\hline & Tilt Rotor & 200 & 300 & \multicolumn{2}{|c|}{ Same as Helicopter } \\
\hline \multirow{2}{*}{ Commercial } & Multi Rotor & 40 & 60 & 70 & 110 \\
\hline & Helicopter & 80 & 130 & 330 & 550 \\
\hline
\end{tabular}

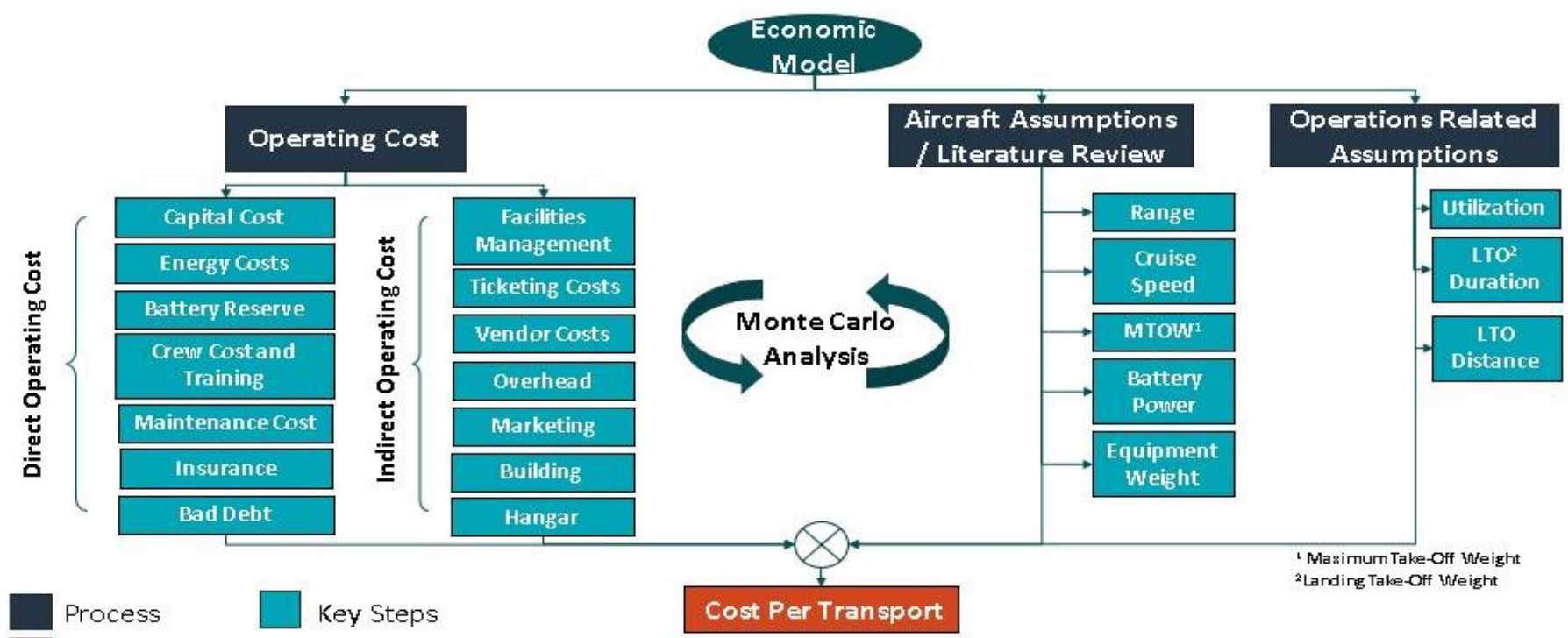

Figure 3. Supply economic model for an air ambulance.

\section{Analysis and Findings}

A preliminary analysis found that the total transport time for ground transportation was faster for distances less than 32 to $40 \mathrm{~km}(\mathrm{~km})$ (20 to 25 miles) than eVTOLs as shown in Figure 4. Based on current technological and economic assumptions, the study finds that eVTOLs are not likely to compete with ground ambulances for medical transportation less than $40 \mathrm{~km}$ ( 25 miles). However, the study finds that hybrids could compete for market share with ground ambulances for distances between 24 and $32 \mathrm{~km}$ (15 to 20 miles). 


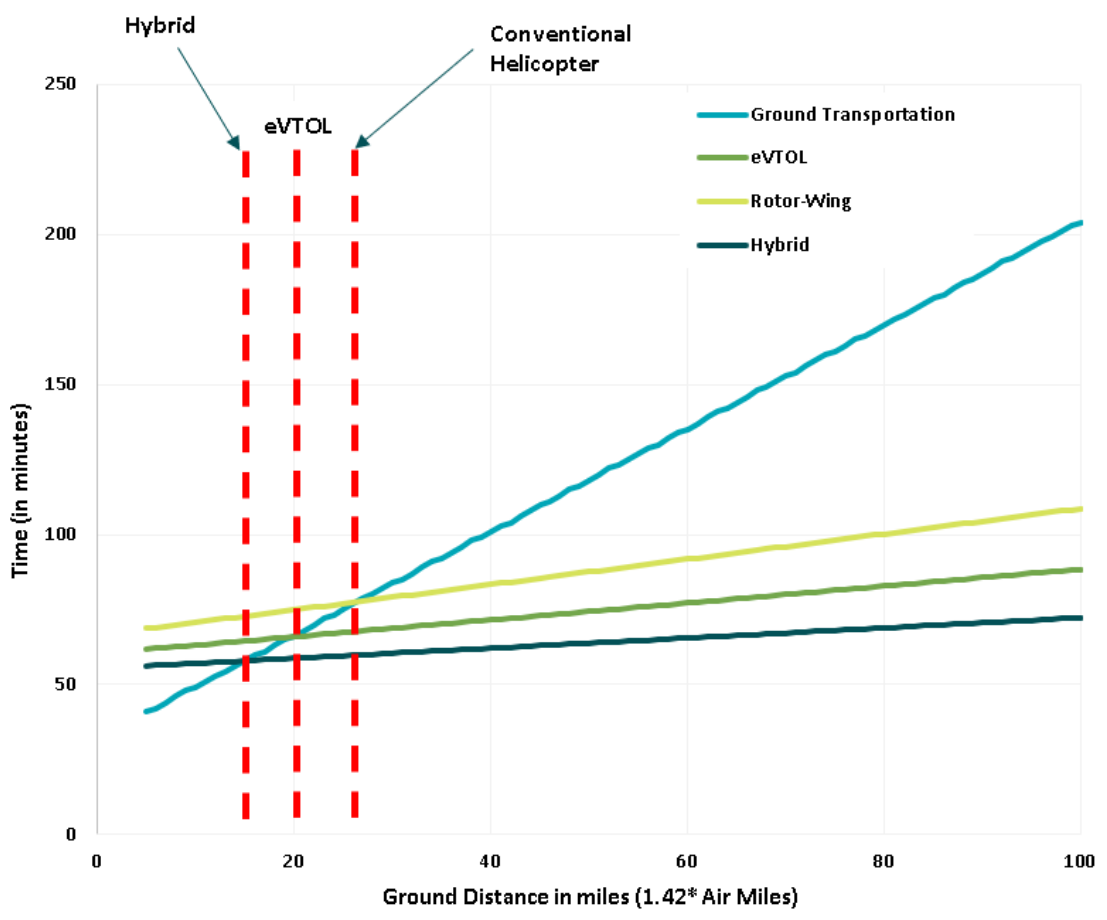

Figure 4. Transportation times as a function of distance for different types of ambulances.

The authors also compared hybrid and eVTOL aircraft to fixed wing aircraft as shown in Figure 5. Due to differences in range between hybrid and eVTOL aircraft versus fixed wing aircraft, the study finds that hybrids and eVTOLs are not likely to compete with the fixed-wing market without improvements in range. While the study finds that hybrids may be suitable for specialty care transport, given that this service represents less than one percent of ambulance trips and requires a larger aircraft with more crew, the study concludes that eVTOL and hybrids will only compete with helicopters in the near-term.

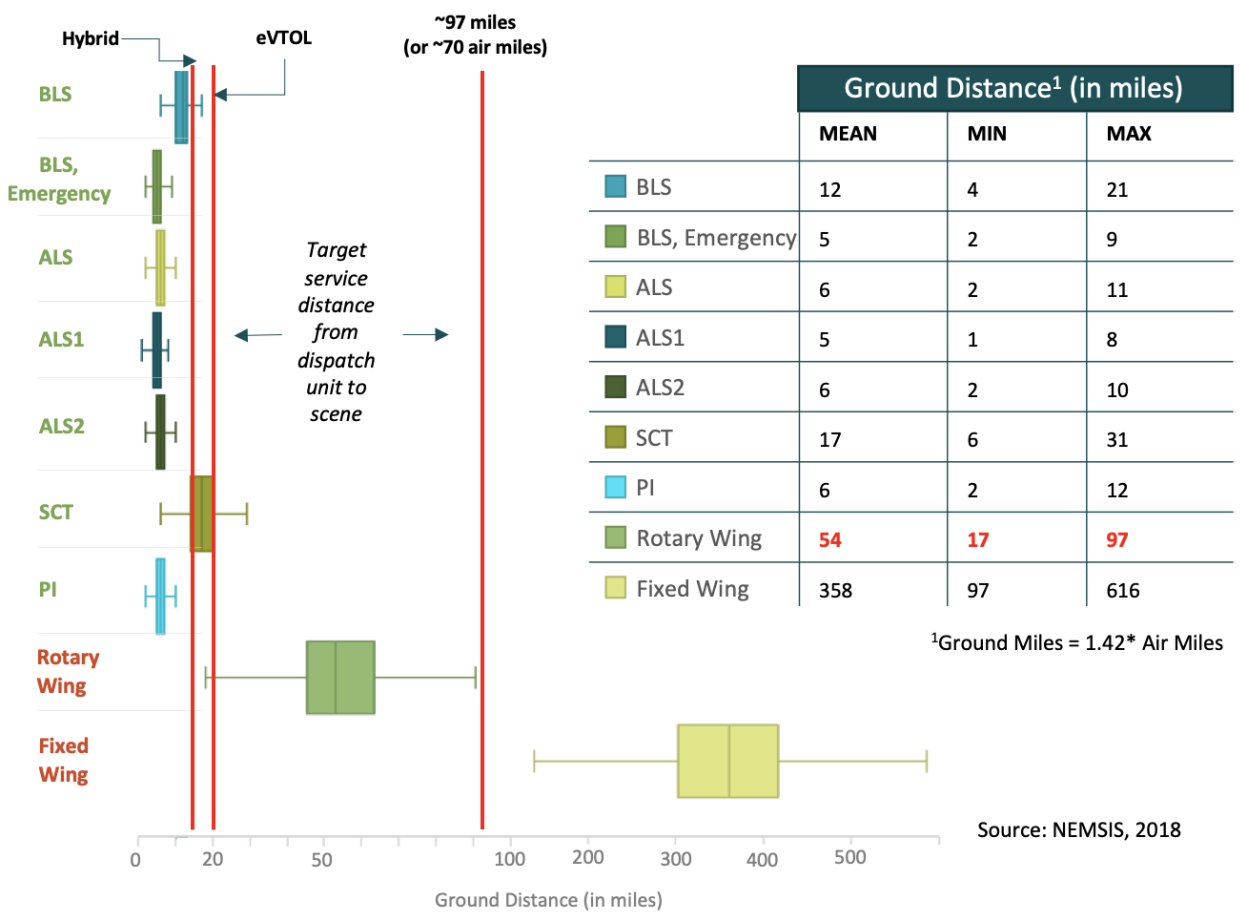

Figure 5. Typical range requirements based on CMS Service Level. 
Monte Carlo was performed on all the operating assumptions highlighted in Table 3, aircraft-related assumptions in Table 4, and additional simulation assumptions in Table 5. For example, some of the additional assumptions applied included parameters on operations, costs, and other factors that could influence the business model such as personnel costs, energy costs, and profit margins. After performing 10,000 iterations of the Monte Carlo simulation, it was observed that the median cost of operating an eVTOL air ambulance is approximately 9000 USD per medical transport. The median cost of operating a hybrid air ambulance is 9800 USD per medical transport compared to 10,000 USD per transport for a rotary-wing helicopter [5] (Figure 6). In comparison, a medical transport using a ground ambulance costs approximately 500 USD per a transport. However, a high degree of uncertainty was observed primarily due to the assumptions associated with payroll and number of transports. In summary, eVTOLs and hybrid aircraft are not necessarily the more cost-effective option for aeromedical use cases when operated similarly to air ambulances using helicopters.

Table 5. Monte Carlo simulation assumptions.

\begin{tabular}{ccc}
\hline Parameter & Min & Max \\
\hline Cruise Altitude (ft) & 500 & 5000 \\
Medical Equipment Weight (lb) & 200 & 400 \\
Pilot Training (USD per year) & 10,000 & 30,000 \\
Paramedic and EMT Training (USD per year) & 10,000 & 20,000 \\
Indirect Operating Cost (\% of DOC) & $5 \%$ & $50 \%$ \\
Bad Debt (\% of Operating Cost) & $10 \%$ & $20 \%$ \\
Electricity Price (USD/kwh) & 0.1 & 0.3 \\
Profit Margin (\% of Cost) & $10 \%$ & $30 \%$ \\
Disembarkation Time (in mins) & 3 & 5 \\
Climb Descend Distance (miles) & 1 & 2 \\
Energy Conversion Efficiency (\%) & $90 \%$ & $98 \%$ \\
\hline
\end{tabular}

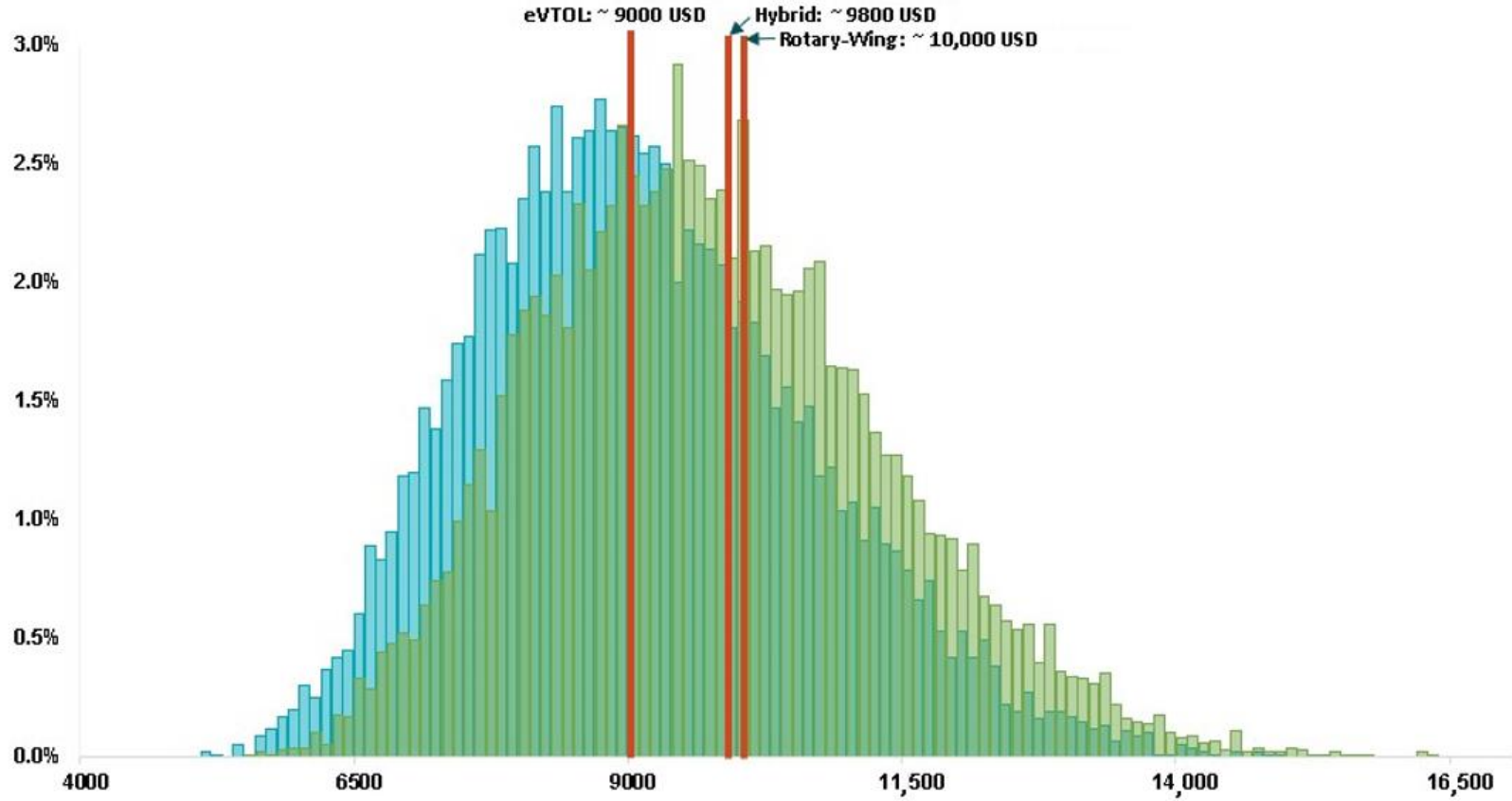

Figure 6. Monte Carlo analysis of total cost per aeromedical transport.

Figure 7 summarizes the categorical fixed and operational costs for eVTOL, hybrid, and rotary-wing aircraft. Fixed costs account for approximately $80 \%$ of the overall cost of transport. As such, improvements in aircraft efficiency do not notably improve the cost per 
medical transport. Fixed costs can be reduced if they are spread over a greater number of medical transports (e.g., increasing aircraft utilization). However, for an eVTOL aircraft, the number of transports will also be impacted by battery recharging times that increase total call time and reduce availability of eVTOL compared to hybrid and gas-powered aircraft and rotorcraft. Both increased aircraft utilization and increased aircraft unavailability time due to charging are particularly unfavorable for the air ambulance use case because both can notably reduce dispatch reliability.

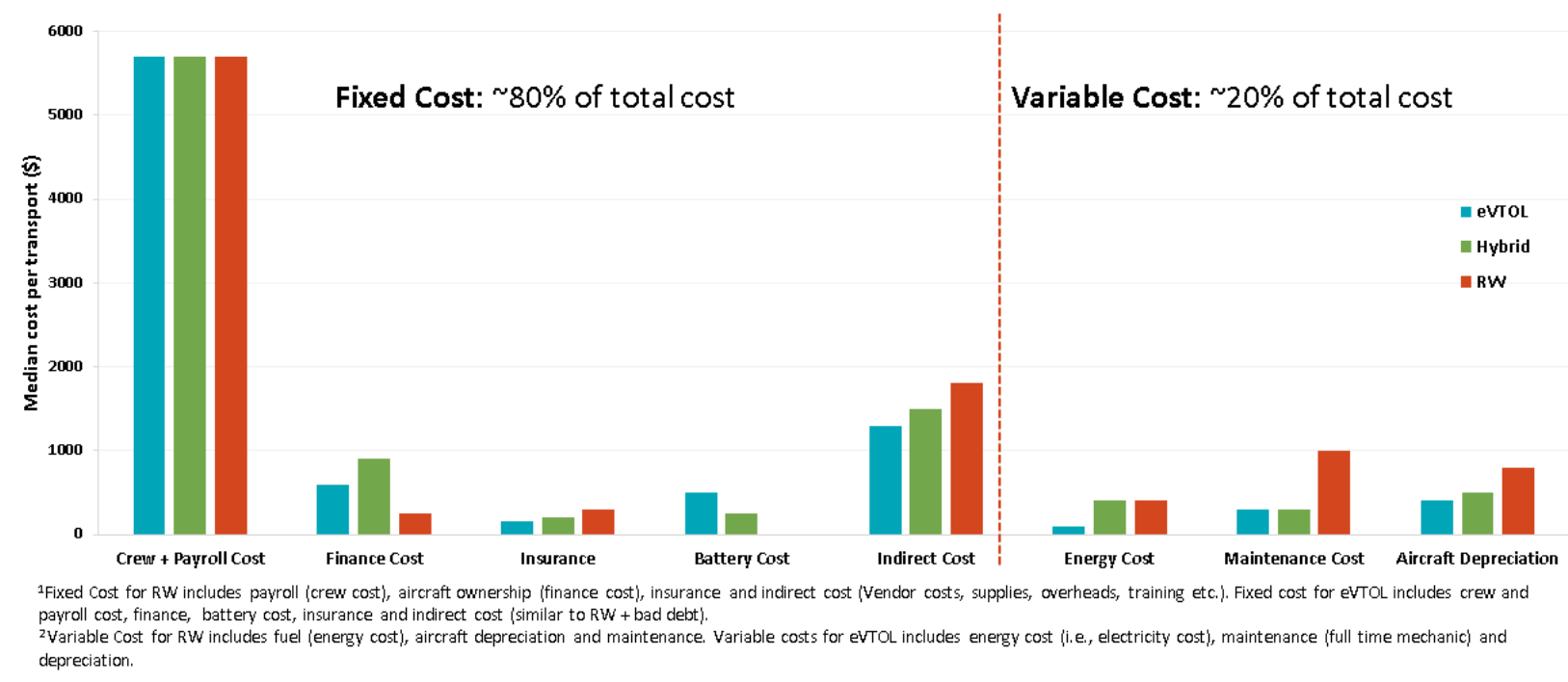

Figure 7. Fixed and variable cost comparison of eVTOL, hybrid, and rotary-wing (RW) aircraft.

\subsection{Revised Concept of Operations and Battery Swapping Scenarios}

The analysis finds that an eVTOL air ambulance battery range and weight (approximately 3500 pounds) reduces the ability for this aircraft to serve longer medical transports. Assuming a conservative average charging capability of 125 kilowatts $(\mathrm{kW})$, the study finds that an eVTOL's time required to bring the aircraft back to service would be $\sim 3.34$ h (200 min), which is significantly higher than rotorcraft (which is typically $30 \mathrm{~min}$ ). To achieve the same total call time as rotorcraft, eVTOLs would need to reduce the time required to return back to service by $145 \mathrm{~min}$. The total call time of eVTOLs is $275 \mathrm{~min}$ compared to $130 \mathrm{~min}$ for helicopters. The authors applied two different scenarios to address this challenge.

The first scenario proposes a revised operational concept. In the original operational concept, the patient was transported from the scene to the medical facility, however the aircraft does not begin charging until the patient disembarks the aircraft. In this scenario, the authors explored the potential to start battery charging during patient disembarkation (approximately five minutes).

The second scenario proposes swapping batteries when the eVTOL returns to the base after each mission to reduce downtime associated with recharging. Battery swapping was estimated to take approximately five minutes and the cost of an extra battery was added to the cost calculations. It was assumed that staff and equipment required to swap the batteries are included as part of IOCs. In this scenario, total call time was compared for eVTOLs, hybrid, and rotorcraft. While dispatch, chute, and scene time were estimated to remain the same for all three aircraft, without battery swapping return time increased significantly for eVTOLs. However, with the addition of battery swapping, eVTOLs and hybrid aircraft can be utilized approximately $35 \%$ more than existing rotorcraft, potentially reducing cost per transport by about $30 \%$ (Figure 8 ). 


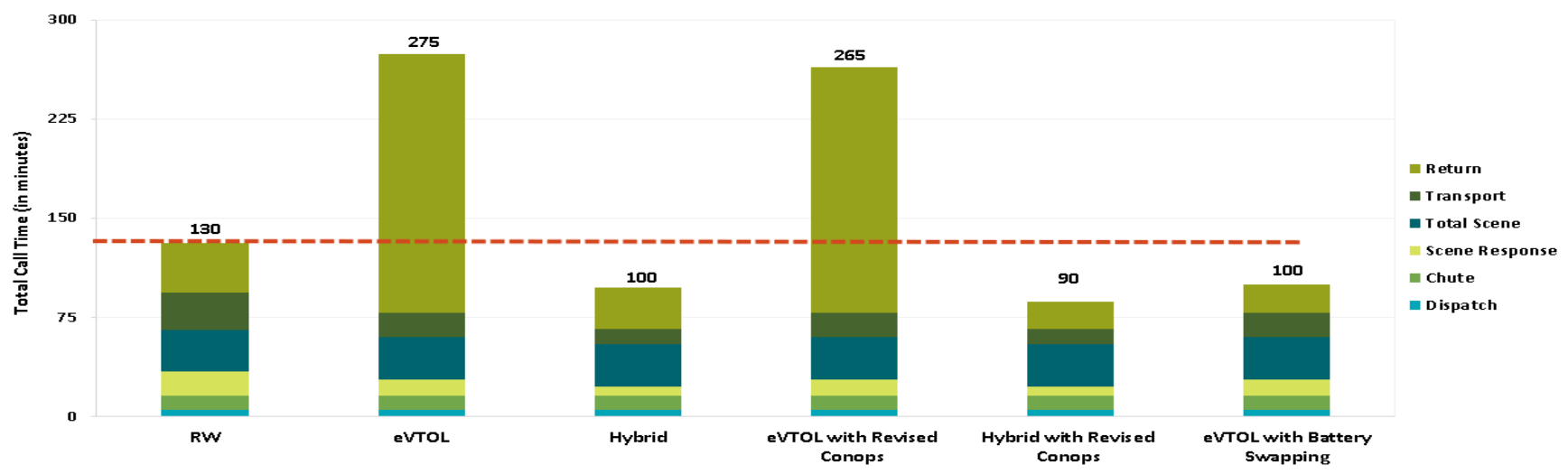

Figure 8. Comparison of total call time for various aircraft and scenarios.

\section{2. eVTOL and Hybrid Aircraft Dispatch Reliability and Market Potential}

The authors used the study findings to assess the suitability of eVTOLs and hybrid aircraft for the existing rotary-wing aeromedical market using demand modeling. To do this, the authors established a dispatch reliability model to calculate the probability of events for which an eVTOL or hybrid ambulance was unavailable. The dispatch reliability is calculated by the total number of events in which an air ambulance is available divided by the total number of events where an air ambulance would be dispatched if available. The demand model for aeromedical service estimates the effective number of transports required compared to those that could be performed, hourly demand distribution, and dispatch reliability for modeling for different scenarios (Figure 9). As previously noted, with the exception of a battery swapping scenario, the increase in total call time for eVTOL aircraft decreased the number of transports these aircraft could complete, increasing overall costs. To achieve a comparable cost level to existing rotorcraft, eVTOLs would have to perform a greater number of transports. However, hybrid aircraft and eVTOLs with battery swapping capabilities reduced total call time, making them a potentially more attractive economic replacement for existing rotorcraft. For modeling purposes, the authors assumed an average weekly distribution across all bases in the U.S. On average, demand was generally lowest between $12 \mathrm{AM}$ and $6 \mathrm{AM}$, and typically peaked between $12 \mathrm{PM}$ and $6 \mathrm{PM}$ each day of the week. The late night accounted for approximately $10 \%$ of total aeromedical trips compared to $40 \%$ during the mid-day period. Finally, the authors estimated dispatch reliability by calculating the probability of events where an eVTOL or hybrid aircraft would be unavailable.

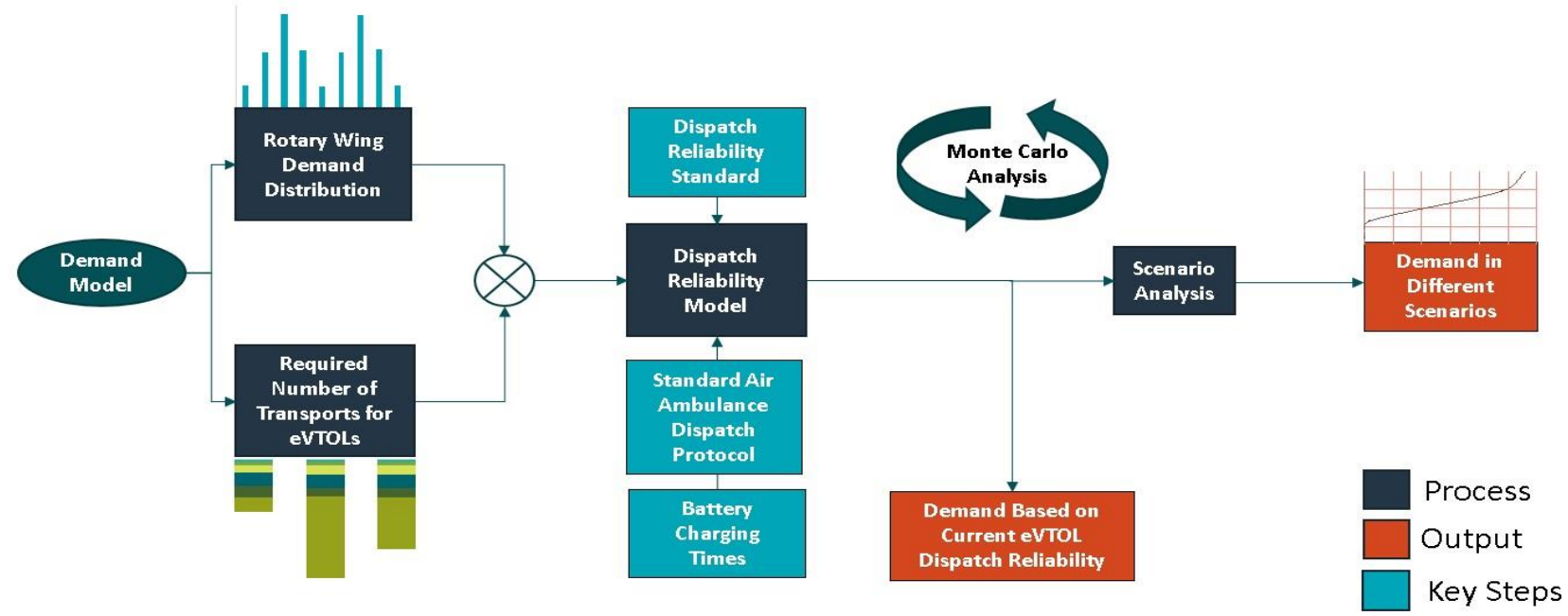

Figure 9. Demand model for air ambulances. 
Aeromedical transport follows established dispatch protocols to maximize the safety and benefits of air ambulances. Common factors that influence a dispatcher's use of an air ambulance include the need to minimize patient transport time to a medical facility, a patient requiring time critical care from a medical facility that is further away, and a patient requiring critical care support not available through ground ambulances. Dispatchers may also opt for an air ambulance when an area is not appropriate for ground transportation or lacks EMS coverage. However, in order for a dispatcher to use an aeromedical service, passenger weight must be within allowable limits, there must be a landing facility at or near the destination medical center, and both current and forecast weather conditions must be suitable for the air transport. Because eVTOLs require an increased number of transports to become economically viable, an increased number of transports also increases the probability that an aircraft is not available for other calls, reducing the dispatch reliability for eVTOLs. The probability model estimates a dispatch reliability of approximately $90 \%$ for eVTOLs, which is considerably lower than the desired industry goal of approximately 99\% (Figure 10). However, when distributing demand on an hourly basis, the model found that the dispatch reliability of eVTOLs drops to $10 \%$ between 12 AM and 6 AM compared to $100 \%$ dispatch reliability for rotary-wing and hybrid aircraft.

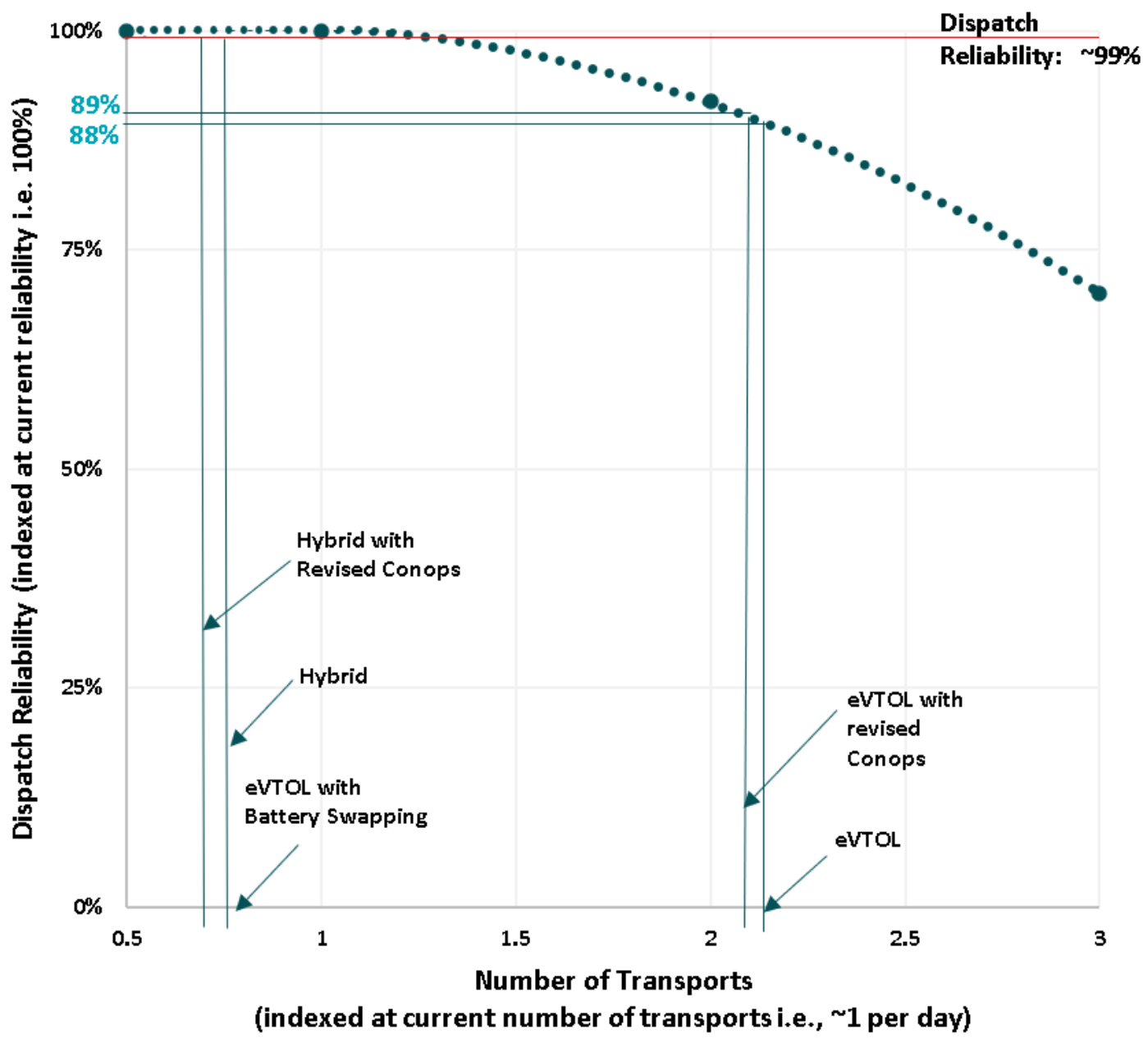

Figure 10. Dispatch reliability on air ambulances.

As noted earlier, to achieve the same level of dispatch reliability as rotorcraft, eVTOLs need to reduce its total call time by $145 \mathrm{~min}$. Therefore, to achieve this, reduced charging times would be necessary to reduce the time required for eVTOLs to return back to service for another mission. One way to achieve reduction in charging times would be to use super chargers with higher power available. As indicated earlier, this research uses 125 
$\mathrm{kW}$ chargers that leads to charging times of $200 \mathrm{~min}$. Therefore, battery recharging times would need to be reduced by a factor of four for eVTOLs (to $50 \mathrm{~min}$ ) to reduce eVTOLs total call time to $125 \mathrm{~min}$ (Figure 11). The reduction in total call time coupled with similar dispatch reliability and cost per ambulance trip is required for eVTOLs to effectively compete with rotorcraft in the aeromedical market. Theoretically, while eVTOLs with battery swapping capabilities and hybrid aircraft could serve this market, innovations that reduce charge times and/or simplify the process of swapping batteries are needed for eVTOLs to effectively provide air ambulance service. However, swapping heavy batteries would require specialized equipment and training (e.g., industrial battery handling and lifting accessories).

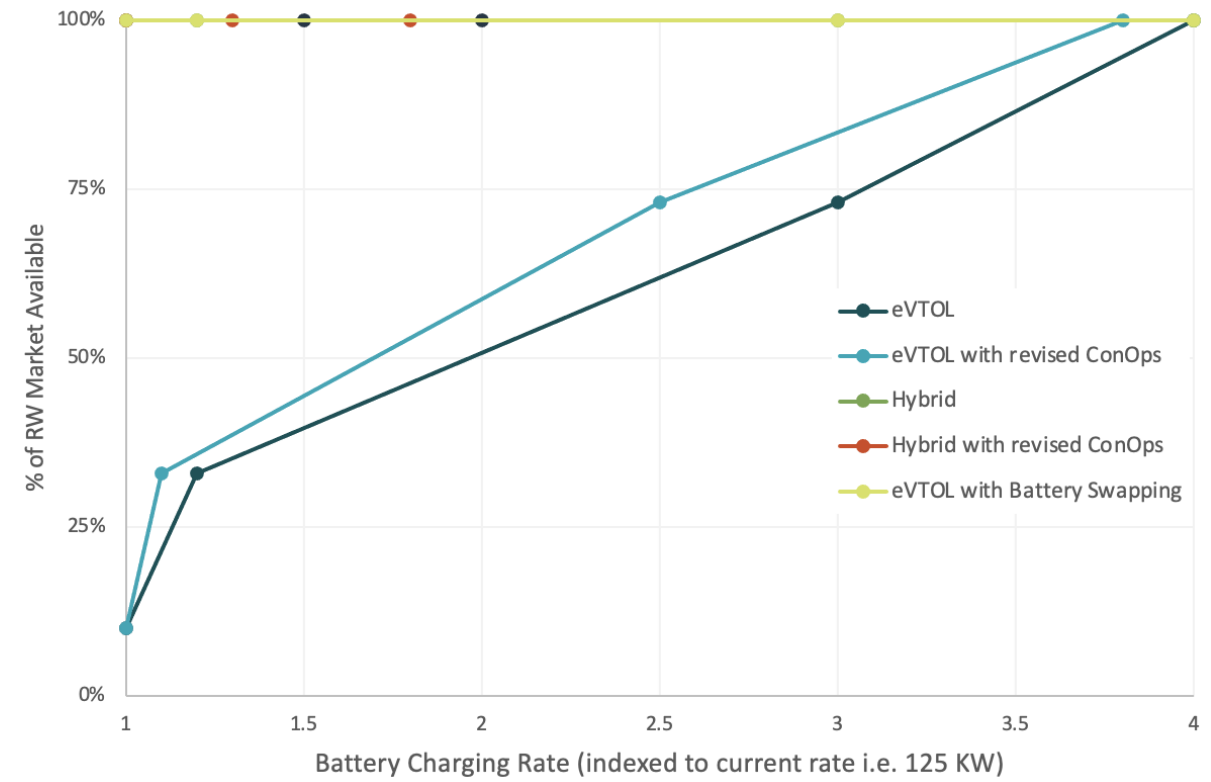

Figure 11. Impact of fast charging on eVTOLs ability to capture rotary-wing market share.

\section{Conclusions}

Although a number of technical and social concerns have been raised about AAM, early use cases for emergency response and aeromedical transport may be key to demonstrating early use cases and building public acceptance of emerging aviation technologies. However, the ability for AAM to serve aeromedical trips will be highly dependent on technological capabilities, economics, operational concept, and the ability to provide fast and reliable medical transport in a large variety of scenarios.

This study concludes that the application of eVTOL aircraft in an aeromedical setting could confront a number of operational and economic challenges compared to hybrid VTOL aircraft and more traditional helicopters. The study concludes that the cost of air ambulance operation is primarily driven by personnel requirements irrespective of aircraft type. In order for eVTOLs to be a suitable replacement for existing aircraft, they must reduce costs, improve operational capability, or both. However, the analysis shows that battery range and weight limits the ability for eVTOL to serve longer medical transports. The analysis also concludes that an eVTOL's charging time required to bring an aircraft back to service reduces the ability for this aircraft to provide reliable aeromedical transport that is comparable with hybrid and gas-powered aircraft currently serving the marketplace.

In order to maintain a high-level of operational readiness, this exploratory study suggests that aircraft manufacturers and air ambulance service providers may need to emphasize technological improvements and changes in operational procedures that reduce charge times, increase electric range, and explore other innovations such as battery swapping and alternative fuel aircraft. Additionally, the deployment of mixed aircraft fleets with different capabilities may be able to help bridge the gap as more reliable and 
cost-effective aircraft for aeromedical use become available. Finally, eVTOLs may be able to enter the aeromedical market by serving non-emergency uses (e.g., patient and medical personnel transport, delivery of medical supplies, etc.). These uses require fewer personnel and could allow eVTOLs to enter the marketplace at a lower cost than existing aircraft. More research is needed to study the potential opportunities and challenges of using VTOL aircraft powered by alternative fuels such as hydrogen for aeromedical transportation.

Author Contributions: Conceptualization, R.G.; Formal analysis, R.G.; Methodology, R.G.; Project administration, A.C.; Writing-review \& editing, A.C. All authors have read and agreed to the published version of the manuscript.

Funding: This research was funded by the National Aeronautics and Space Administration (NASA), grant number NNH13CH54Z.

Informed Consent Statement: Not applicable.

Acknowledgments: The authors would like to thank NASA and the NASA market study strategic advisory group for their role in supporting this research. The authors would like to give special thanks to Nancy Mendonca and Michael Patterson for supporting this work. The contents of this article reflect the views of the authors and do not necessarily indicate sponsor acceptance.

Conflicts of Interest: The authors declare no conflict of interest. The funders had no role in the design of the study; in the collection, analyses, or interpretation of data; in the writing of the manuscript; or in the decision to publish the results.

\section{References}

1. Goyal, R.; Reiche, C.; Fernando, C.; Cohen, A. Advanced air mobility: Demand analysis and market potential of the airport shuttle and air taxi markets. Sustainability 2021, 13, 7421. [CrossRef]

2. Cohen, A.; Shaheen, S.; Farrar, E. Urban air mobility: History, ecosystem, market potential, and challenges. IEEE Trans. Intell. Transp. Syst. 2021, 22, 6074-6087. [CrossRef]

3. Cohen, A.; Shaheen, S. Urban air mobility: Opportunities and obstacles. In International Encyclopedia of Transportation; Elsevier: Amsterdam, The Netherlands, 2021.

4. Thipphavong, D.P.; Apaza, R.; Barmore, B.; Battiste, V.; Burian, B.; Dao, Q.; Feary, M.; Go, S.; Goodrich, K.H.; Homola, J.; et al. Urban air mobility airspace integration concepts and considerations. In Proceedings of the 2018 Aviation Technology, Integration, and Operations Conference, Atlanta, GA, USA, 25-29 June 2018.

5. Association of Air Medical Services. Atlas \& Database of Air Medical Services. 2017. Available online: https://aams.org/default. aspx (accessed on 18 September 2021).

6. Lu, D. Drones keep an eye on people failing to social distance. New Sci. 2020, 246, 10. [CrossRef]

7. Thiruvengadam, M. Social Distancing Drones are Watching Gatherings in Singapore and Sending Footage to Police. Travel + Leisure, 12 August 2020.

8. Anggraeni, S.; Maulidina, A.; Dewi, M.W.; Rahmadianti, S.; Rizky, Y.P.C.; Arinalhaq, Z.F.; Usdiyana, D.; Nandiyanto, A.B.D.; Al-Obaidi, A. The deployment of drones in sending drugs and patient blood samples COVID-19. Indones. J. Sci. Technol. 2020, 18-25. [CrossRef]

9. Pennic, F. ‘Pandemic Drone' Could Detect Virus Symptoms like COVID-19 in Crowds. HIT Consultant, 27 March 2020.

10. Nellis, S. California Startup Aims to Monitor Social Distancing and Face Masks Using Drones. Reuters, 12 June 2020.

11. Kelley, A. Talking Drones Issuing Social Distancing Warnings in New Jersey. The Hill, 9 April 2020.

12. Heater, B. UPS and CVS Will Offer Prescription Drug Delivery to Florida Community via Drone. TechCrunch, 27 April 2020.

13. Gallagher, K. Humanitarian Aid Gets a Helping Hand from UAS Technology. Simulyze, 1 September 2016.

14. Ackerman, E.; Koziol, M. The blood is here: Zipline's medical delivery drones are changing the game in Rwanda. IEEE Spectr. 2019, 56, 24-31. [CrossRef]

15. Lamptey, E.; Serwaa, D. The use of zipline drones technology for COVID-19 samples transportation in Ghana. HighTech Innov. J. 2020, 1, 67-71. [CrossRef]

16. Umtesi, G.; Bigirimana, J.B.; Ursaro, S.; Uwizeye, F.R.; Nahimana, E.; Tuyishimire, J.D.; Mubilgi, J.M.; Uwinkindi, F.; Kateera, F. Cancer care delivery innovations, experiences and challenges during the COVID-19 pandemic: The Rwanda experience. J. Glob. Health 2021, 11, 03067. [CrossRef] [PubMed]

17. Phillips, J. Medical Unmanned Aerial System for Organ Transplant Delivery. 2019. Available online: http://rgdoi.net/10.13140 /RG.2.2.28471.57769 (accessed on 21 December 2021).

18. Euchi, J. Do drones have a realistic place in a pandemic fight for delivering medical supplies in healthcare systems problems? Chin. J. Aeronaut. 2021, 34, 182-190. [CrossRef]

19. Steenhoff, T.C.; Siddiqui, D.I.; Zohn, S.F. EMS Air Medical Transport; StatPearl Publihing: Treasure Island, FL, USA, 2021. 
20. Straubinger, A.; Rothfeld, R.; Büchter, K.-D.; Kaiser, J.; Plötner, K.O. An overview of current research and developments in urban air mobility-Setting the scene for UAM introduction. J. Air Transp. Manag. 2020, 87, 101852. [CrossRef]

21. Chappelle, C.; Li, C.; Vascik, P.D.; Hansman, R.J. Opportunities to enhance air emergency medical service scale through new vehicles and operations. In Proceedings of the 2018 Aviation Technology Integration, and Operations Conference, Atlanta, GA, USA, 25-29 June 2018.

22. Mihara, Y.; Pawnlada, P.; Nakamoto, A.; Nakamura, T.; Nakano, M. Cost analysis of eVTOL configuration design for an air ambulance system in Japan. In Proceedings of the 8th International Engineering Systems Symposium (CESUN 2021), Charlottesville, VA, USA, 10-12 October 2021.

23. National Emergency Medical Services Information Systems. NEMSIS Annual Public Data Report 2019; NEMSIS: Salt Lake City, UT, USA, 2019.

24. Federal Interagency Committee on Emergency on Emergency Medical Services. 2011 National EMS Assessment; U.S. Department of Transportation: Washington, DC, USA, 2011.

25. Reich, C.; Goyal, R.; Cohen, A.; Serrao, J.; Kimmel, S.; Fernando, C.; Shaheen, S. Urban Air Mobility Market Study; National Aeronautics and Space Administration: Washington, DC, USA, 2018; pp. 1-160. Available online: https://ntrs.nasa.gov/ citations / 20190001472 (accessed on 25 December 2021).

26. U.S. Centers for Medicare \& Medicaid Services. Medicare Benefit Policy Manual Chapter 10: Ambulance Services. Available online: https://www.cms.gov/Regulations-and-Guidance/Guidance/Manuals/downloads/bp102c10.pdf (accessed on 18 October 2021).

27. National Emergency Medical Services Information System. National Emergency Medical Services Information System. 2019. Available online: https:/ / nemsis.org/2018-public-release-research-dataset-available/ (accessed on 21 September 2021).

28. XTI. XTI Aircraft-Air Mobility Revolutionized. Available online: https://www.xtiaircraft.com/xti-triFan-600 (accessed on 18 October 2021).

29. Vertical Flight Society. eVTOL Aircraft Directory. Available online: https:/ / evtol.news/aircraft (accessed on 18 October 2021).

30. Code of Federal Regulations. Title 14 Code of Federal Regulations Part 91. Available online: https://www.wikihow.com/Citethe-Code-of-Federal-Regulations (accessed on 18 October 2021).

31. Nykvist, B.; Nilsson, M. Rapidly falling costs of battery packs for electric vehicles. Nat. Clim. Chang. 2015, 5, 329-332. [CrossRef]

32. U.S. Bureau of Labor Statistics. Industries at a Glance: NAICS Code Index. Available online: https://www.bls.gov/iag/tgs/iag_ index_naics.htm (accessed on 18 October 2021). 